\section{JURNAL ABDIMAS

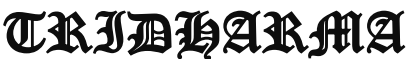

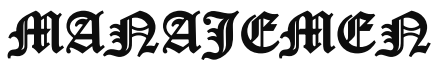

P-ISSN 0000-0000, E-ISSN 0000-0000

Jurnal ABDIMAS Vol. 1,No.1, Agustus 2019, Hal (1-7)

@Prodi Manajemen Fakultas Ekonomi Universitas Pamulang

Email: abdimasjurnal.unpam@gmail.com Telp: (021) 741-2566

\title{
PELATIHAN MANAJEMEN KEUANGAN BAGI NELAYAN KEPULAUAN SERIBU PASCA PENJUALAN HASIL TANGKAPAN IKAN
}

\author{
Khotimatus Sadiyah, Endang Nurita,Rosa Lesmana \\ Dosen Ekonomi Fakultas Ekonomi Universitas Pamulang \\ Email diyah.khotimatus@gmail.com
}

\begin{abstract}
ABSTRAK
Pengabdian masyarakat ini berjudul "Pelatihan Manajemen Keuangan Bagi Nelayan Kepulauan Seribu Pasca Penjualan Hasil Tangkapan Ikan" bertujuan untuk memberikan pemahaman kepada nelayan tentang manajemen keuangan pasca panen ikan dan memotivasi nelayan agar menerapkan ilmu manajemen keuangan agar siklus keuangan mereka menjadi stabil. Metode pelaksanaan pengabdian ini dilakukan dalam beberapa kegiatan yaitu tahap persiapan yang meliputi survei lokasi, pemantapan dan penentuan lokasi, penyusunan bahan materi pelatihan, penyusunan jadwal pelatihan,dan pembagian tugas tim pengabdian, selanjutnya tahap pelaksanaan Pelatihan. Sebelum tahap sosialisasi sebelum kegiatan pengabdian dilaksanakan terlebih dahulu dilakukan tahap silaturahmi kepada ketua RT Kepulauan Seribu dan menyampaikan maksud serta tujuan pengabdian. Pada tahap ini juga dilakukan jalinan kerjasama dan menentukan jadwal kegiatan pengabdian. Tim pelaksana kegiatan pengabdian pada masyarakat adalah dosen-dosen Universitas Pamulang sebanyak 5 orang. Tim pengabdian memberikan materi tentang pelatihan manajemen keuangan pasca panen dan memotivasi nelayan agar menerapkan ilmu manajemen keuangan agar siklus pengolahan keuangan mereka berjalan stabil.

Kesimpulan dari pengabdian ini adalah nelayan kepulauan seribu masih salah dalam pengelolaan keuangan pasca penjualan ikan, tidak adanya manajemen keuangan yang baik sehingga hasil tangkapan banyak digunakan untuk hal konsumtif yang berdampak pada kesulitan keuangan pada saat tidak adanya hasil panen. Harapan kami malalui pengabdian ini dapat memberikan pengetahuan dan wawasan yang dapat meningkatkan pengetahuan dan ketrampilan nelayan dalam mengelola keuangan mereka dengan baik.
\end{abstract}

\section{Kata Kunci: Manajemen Keuangan, Nelayan, Penjualan}




\section{JURNAL ABDIMAS

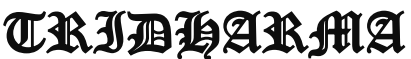

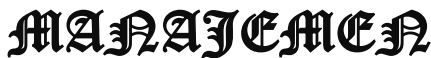

P-ISSN 0000-0000, E-ISSN 0000-0000

Jurnal ABDIMAS Vol. 1,No.1, Agustus 2019, Hal (1-7)

@Prodi Manajemen Fakultas Ekonomi Universitas Pamulang

Email: abdimasjurnal.unpam@gmail.com Telp: (021) 741-2566

\begin{abstract}
This community service entitled "Financial Management Training for Thousand Islands Fishermen After the Sale of Fishing Products" aims to provide fishermen with an understanding of financial management after fish harvesting and motivate fishermen to apply financial management so that their financial cycles become stable. The method of implementing this service was carried out in several activities, namely the preparation stage which included site surveys, stabilization and determination of locations, preparation of training material, preparation of training schedules, and division of duties of the service team, then the implementation phase of Training. Before the socialization stage before the service activities are carried out, the first stage is the gathering to the head of the Seribu Islands RT and to convey the purpose and purpose of the service. At this stage collaboration is also carried out and the schedule of service activities is determined. The implementation team of community service activities is 5 people from Pamulang University lecturers. The service team provided material on postharvest financial management training and motivated fishermen to apply financial management knowledge so that their financial processing cycles were stable

The conclusion of this service is that thousand islands fishermen are still wrong in financial management after the sale of fish, there is no good financial management so the catches are widely used for consumptive matters which have an impact on financial difficulties when there are no crops. It is our hope that through this service we can provide knowledge and insights that can improve the knowledge and skills of fishermen in managing their finances well.
\end{abstract}

\title{
Keywords: Financial Management, Fishermen, Sales
}

\section{PENDAHULUAN}

Ada 110 pulau di seberang daratan perkotaan Jakarta, bila ditotal luas daratannya $8,70 \mathrm{~km}$ persegi. Demikian Badan Pusat Statistik (BPS) menyebut jumlah pada laopran tahun 2017, Jadi, meski namanya Kepulauan Seribu, jumlah pulaunya sendiri tak sampai seribu. Pulau-pulau kecil tanpa permukiman warga jumlahnya lebih banyak.

$\begin{array}{rlrr} & \text { "Namanya memang Pulau } \\ \text { Seribu tapi sebenarnya adalah } & 110\end{array}$ pulau. Ada 11 pulau berpenghuni, sisanya adalah pulau resor, pulau konservasi, dan pulau cagar budaya," kata Bupati Kepulauan Seribu Husein Murad di RPTRA Pulau Panggang, Selasa (19/2/2019)

Menurut data BPS, penduduk Kepulauan Seribu berjumlah 23.939 jiwa pada 2018. Angkatan kerja yang tercatat setahun sebelumnya ada 9.959 orang. Ada 3.375orang nelayan di Kepulauan Seribu. Mayoritas 


\section{JURNAL ABDIMAS

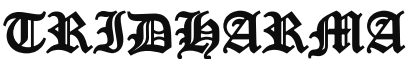

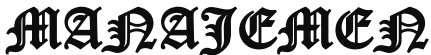

P-ISSN 0000-0000, E-ISSN 0000-0000

Jurnal ABDIMAS Vol. 1,No.1, Agustus 2019, Hal (1-7)

@ Prodi Manajemen Fakultas Ekonomi Universitas Pamulang

Email: abdimasjurnal.unpam@ gmail.com Telp: (021) 741-2566 penduduknya masih mengandalkan dari (pekerjaan) nelayan"

Meski mayoritas penduduk Kepulauan Seribu bermata pencaharian nelayan, namun kawasan ini bergerak menuju arah kawasan wisata. Kepulauan Seribu masuk menjadi salah satu dari 10 Destinasi Wisata Prioritas atau biasa disebut "10 Bali Baru" yang ditetapkan pemerintah sejak 2016.

Permasalahan yang dihadapi nelayan saat ini adalah salah dalam pengelolaan keuangan pasca penjualan ikan. Karena tidak adanya manajemen keuangan yang baik maka hasil penjualan tangkapan ikan banyak digunakan untuk hal konsumtif hingga berdampak pada mereka ketika tidak ada panen ikan banyak nelayan yang mengalami kesulitan keuangan.

Hal inilah yang menjadi pemikiran beberapa dosen dari fakultas ekonomi program dan fakultas hukum untuk memberikan dan mentransfer ilmu pengetahuan sekaligus bentuk pengabdian kepada lapiasan msyarakat khususnya para nelayan di Kepulauan Seribu agar mereka mampu mengelola keuangan mereka dengan baik hingga disaat-saat tidak panen mereka tetap memiliki simpanan uang tabungan. Berdasarkan masalah tersebut, dirasakan perlu diadakan kegiatan yang dapat memberikan pengetahuan tentang manajemen keuangan bagi nelayan di Kepulauan Seribu yang berjudul “ Pelatihan Manajemen Keuangan Bagi
Nelayan Kepulauan Seribu Pasca Penjualan Hasil Tangkapan Ikan"

\section{RUMUSAN MASALAH}

Berdasarkan latar belakang diatas dapat dirumusan permasalah dalam pelaksanaan pengabdian masyarakat bagi nelayan kepulauan seribu sebagai berikut:

1. Bagaimana memberikan pemahaman kepada nelayan mengenai pengelolaan keuangan yang baik pasca panen ikan?

2. Bagaimana menerapkan manajemen keuangan yang baik dilingkungan Kepualuan Seribu?

\section{TUJUAN PELAKSANAAN}

Tujuan pelaksanaan pengabidian msyarakat di Keulauan Seribu adalah:

1. Memberikan pemahaman kepada nelayan mengenai pengelolaan keuangan yang baik pasca panen ikan.

2. Memotivasi penerapan manajemen keuangan yang baik agar siklus keuangan nelayan menjadi stabil

\section{TINJAUAN PUSTAKA}

\section{Pengertian Manajemen Keuangan}

Pengertian Manajemen Keuangan Menurut Horne dan Wachowicz Jr. (2012:2) dalam bukunya yang berjudul Fundamentals of Financial Management yang telah di alih bahasa menjadi Prinsip-prinsip Manajemen 


\section{JURNAL ABDIMAS

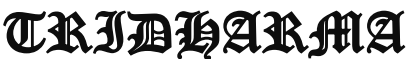

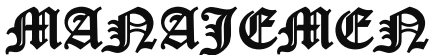

P-ISSN 0000-0000, E-ISSN 0000-0000

Jurnal ABDIMAS Vol. 1,No.1, Agustus 2019, Hal (1-7)

@ Prodi Manajemen Fakultas Ekonomi Universitas Pamulang

Email: abdimasjurnal.unpam@ gmail.com Telp: (021) 741-2566
Keuangan mengemukakan bahwa: "Manajemen keuangan berkaitan dengan perolehan aset, pendanaan, dan manajemen aset dengan didasari beberapa tujuan umum".

Irham Fahmi

(2013:2), mengemukakan bahwa: "Manajemen Keuangan merupakan penggabungan dari ilmu dan seni yang membahas, mengkaji dan menganalisis tentang bagaimana seorang manajer keuangan dengan mempergunakan seluruh sumberdaya perusahaan untuk mencari dana, mengelola dana dan membagi dana dengan tujuan memberikan profit atau kemakmuran bagi para pemegang saham dan suistainability (keberlanjutan) usaha bagi perusahaan."

Teori tersebut menyatakan bahwa manajemen keuangan merupakan suatu kajian dan perencanaan analisis untuk mengetahui mengenai keadaan keuangan yang terjadi pada perusahaan, baik itu mengenai keputusan inventasi, pendanaan bahkan aktiva perusahaan dengan tujuan memberikan profit bagi para pemegang saham dan suistainability (keberlanjutan) usaha bagi perusahaan.

\section{Pengertian Nelayan}

Peraturan Pemerintah Republik Indonesia Nomor 15 Tahun 1990 (15/90) Tentang Usaha Perikanan, bahwa nelayan didefinisikan sebagai orang yang mata pencahariannya melakukan penangkapan ikan. Dalam perstatistikan perikanan perairan umum, nelayan didefinisikan sebagai orang yang secara aktif melakukan operasi penangkapan ikan di perairan umum. Orang yang melakukan pekerjaan seperti membuat jaring, mengangkut alat-alat penangkapan ikan ke dalam perahu atau kapal motor, mengangkut ikan dari perahu atau kapal motor, tidak dikategorikan sebagai nelayan (Departemen Kelautan dan Perikanan 2002). Penangkapan ikan merupakan kegiatan yang bertujuan untuk memperoleh ikan di perairan yang tidak dalam keadaan dibudidayakan dengan alat atau cara apapun, termasuk kegiatan yang menggunakan kapal untuk memuat, mengangkut, menyimpan, mendinginkan, mengolah atau mengawetkannya. Usaha perikanan yang bekerja di bidang penangkapan tercakup dalam kegiatan perikanan tangkap/capture fishery (Wikipedia 2012).

\section{Peta Sosial Ekonomi Nelayan}

Kehidupan nelayan sangat dipengaruhi oleh kondisi laut, perubahan kondisi laut mempengaruhi produktifitas dalam penangkapan ikan dan mendorong nelayan untuk melakukan pergeseran aktifitas kepada hal lain mungkin berkaitan dengan profesinya atau menekuni kegiatan lain. Misalnya pada bulan tertentu misalnya bulan Agustus - Desember kondisi laut cenderung memburuk, dalam keadaan ini para nelayan cenderung tidak turun melaut dan 


\section{JURNAL ABDIMAS

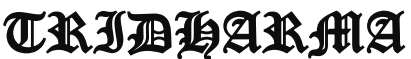

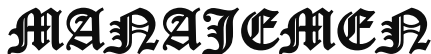

P-ISSN 0000-0000, E-ISSN 0000-0000

Jurnal ABDIMAS Vol. 1,No.1, Agustus 2019, Hal (1-7)

@Prodi Manajemen Fakultas Ekonomi Universitas Pamulang

Email: abdimasjurnal.unpam@ gmail.com Telp: (021) 741-2566 manfaatkan waktu luang dengan memperbaiki perahu ataupun alat tangkap ikan seperti jaring, nelayan lain mungkin saja bekerja sebagai buruh tani, buruh bangunan, berdagang dan lain-lain profesi. Pada kondisi laut yang tidak bersahabat pendapatan nelayan cenderung menurun dan kebutuhan hidupnya tidak terpenuhi, solusi yang ditempuh sebagai pengganti pendapatan adalah menjual peralatan penangkapan, menjual peralatan rumah tangga yang mereka miliki atau terlibat utang piutang dengan para tengkulak untuk dibayar pada saat mereka dapat melaut lagi. Profesi sebagai nelayan hanya ditekuni oleh kalangan terbatas dan marginal. Sumberdaya manusia yang berprofesi sebagai nelayan dicirikan oleh pendidikan dan keterampilan yang rendah, serta kemampuan manajemen yang terbatas. Sitorus (1994) menyatakan bahwa taraf hidup penduduk desa pantai yang sebagian besar nelayan sampai saat ini masih rendah, pendapatan tidak menentu (sangat tergantung pada musim ikan), kebanyakan masih memakai peralatan tradisional dan masih sukar menjauhkan diri dari perilaku boros.

\section{METODE PELAKSANAAN}

Metode kegiatan ini berupa pelatihan kepada nelayan Kepulauan Seribu tentang ilmu manajemen keuangan dan pengelolaan keuangan pasca mereka panen. Setelah diberi pelatihan, selanjutnya mereka dibimbing dalam praktek nyata, diharapkan nelayan dapat menerapkan manajemen keuangan yang baik. Berikut ini adalah tahapan pelatihan yang dilakukan:

1. Tahap Persiapan

Tahap persiapan meliputi:

a. Survei lokasi yang bertujuan untuk mencari tahu permasalahan yang ada di Kepulauan Seribu

b. Pemantapan dan penentuan lokasi sasaran

c. Penyusunan bahan materi pelatihan

2. Tahap Pelaksanaan Pelatihan

Tahap ini memberikan penjelasan manajemen keuangan dan tata cara pengelolaan menajemen keuangan.

3. Tahap Pelatihan

Metode pelatihan yang digunakan adalah metode ceramah, tanya jawab dan simulasi.

\section{HASIL DAN PEMBAHASAN}

Pengabdian Masyarakat yang diselenggarakan pada tanggal 20 Mei 2019 sampai dengan 22 Mei 2019 yang dilakukan oleh dosen-dosen Universitas Pamulang yaitu Khotimatus Sadiyah,S.Si,M.M, Endang Nurita,S.E,M.M, Rosa Lesmana, S.E,M.M, Dr. Nardi Sunardi,S.E M.M dan Dina Novita,S.E,M.M berjalan dengan lancar dan mendapat antusias dari warga nelayan Kepulauan Seribu. Pada kegiatan Pengabdian Masyarakat tersebut para dosen memberikan penjelasan tentang manajemen keuangan, dan memotivasi para 


\section{JURNAL ABDIMAS

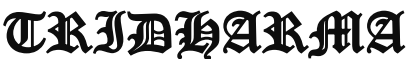

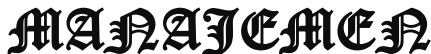

P-ISSN 0000-0000 , E-ISSN 0000-0000

Jurnal ABDIMAS Vol. 1,No.1, Agustus 2019, Hal (1-7)

@Prodi Manajemen Fakultas Ekonomi Universitas Pamulang

Email: abdimasjurnal.unpam@gmail.com Telp: (021) 741-2566 nelayan agar menerapkan ilmu manajemen keuangan di lingkungan mereka hal ini diharapkan agar siklus keuangan pasca hasil tangkapan ikan para nelayan menjadi stabil. Antusiasme nelayan nampak dari banyaknya pertanyaan yang diajukan oleh nelayan kepada para dosen pada sesi diskusi dan tanya jawab. Kegiatan di diakhiri dengan sharing pengalaman antara dosen dan nelayan Kepulauan Seribu.

Kegiatan
masyarakat di Kepulauan Seribu
diharapkan dapat meningkatkan
pengetahuan dan ketrampilan nelayan
dalam mengelola keuangan mereka
dengan baik, dan mampu memberikan
semangat baru bagi dosen- dosen
Universitas Pamulang dalam melakukan
pengabdian kepada seluruh masyarakat.

\section{KESIMPULAN DAN SARAN}

Kesimpulan

Kegiatan pelatihan manajemen keuangan di kepulauan seribu pasca penjualan hasil panen mendapat sambutan yang baik dari warga nelayan hal ini karena minimnya pengetahuan nelayan terhadap menejemen keuangan yang menyebabkan kondisi keuangan pasca penjualan hasil tangkapan ikan menjadi tidak stabil.

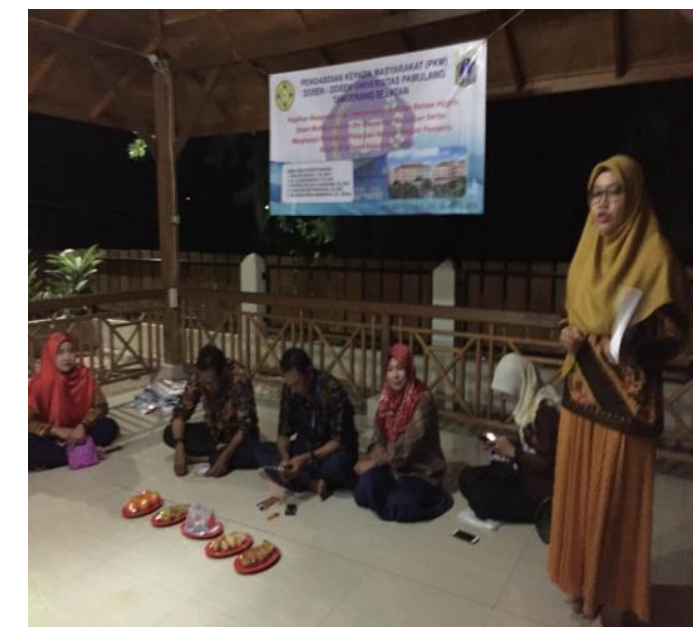

Saran

Kegiatan pengabdian kepada masyarakat ini diharapkan bukan hanya sekedar kegiatan tetapi kedepan akan terus ada kegiatan dibidang manajemen lainnya yang membutuhkan tambahan ilmu pengetahuan sehingga kegiatan Pengabdian Kepada Masyarakat (PKM) ini terus berkelanjutan.

\section{DAFTAR PUSTAKA}

Agus Harjito dan Martono, Manajemen Keuangan. 2011, Edisi Kedua, Cetakan Pertama, Penerbit EKONISIA, Yogyakarta.

Fauzi, Akhmad, 2010, Ekonomi Perikanan,Jakarta:Gramedia Pustaka

Gitosudarmo, Indriyo. 2000. Manajemen Keuangan. Yogyakarta: BPFE.

Http:/www.badan pusat statistik, co.id.

Peraturan Pemerintah Republik Indonesia Nomor 15 Tahun 1990

Rajab Ali Akbar, Strategi Pemberdayaan Nelayan Miskin, 


\section{JURNAL ABDIMAS

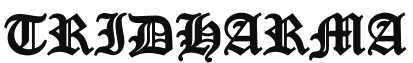 AIA:}

P-ISSN 0000-0000, E-ISSN 0000-0000

Jurnal ABDIMAS Vol. 1,No.1, Agustus 2019, Hal (1-7)

$@$ @rodi Manajemen Fakultas Ekonomi Universitas Pamulang

Email: abdimasjurnal.unpam@ gmail.com Telp: (021) 741-2566

dalamhttp://www.kompasiana.co $\mathrm{m} / 19 / 2 / 2019$.

Sartono, Agus. 2008. Manajemen Keuangan Teori dan Perencanaan keuangan Perusahaan. Gramedia Pustaka Utama, Jakarta

\section{DOKUMENTASI KEGIATAN}
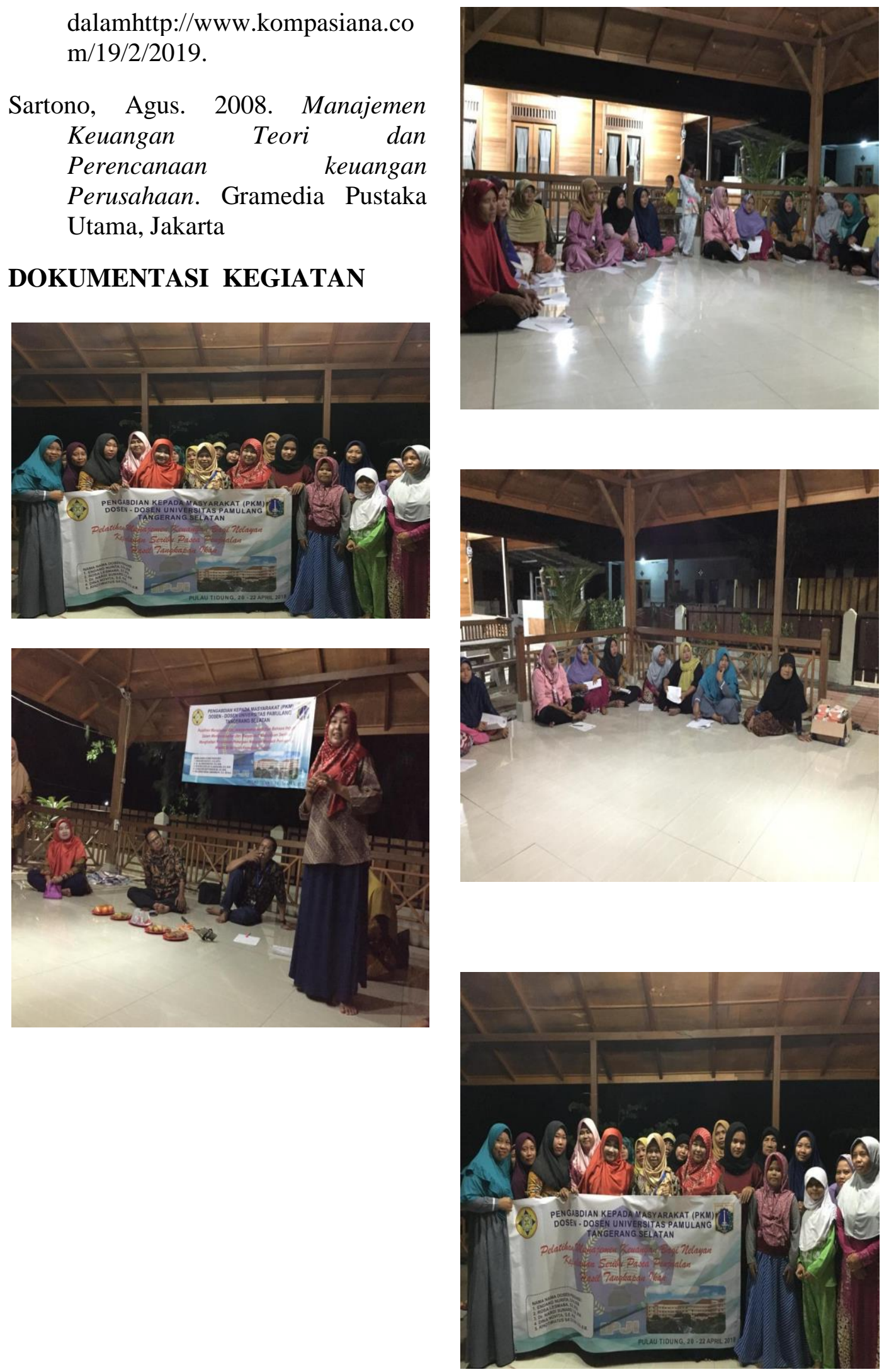